\title{
ТЕХНИКА УСТАНОВЛЕНИЯ, ПРЕОДОЛЕНИЯ И УСТРАНЕНИЯ ПРАВОТВОРЧЕСКИХ ОШИБОК КАК ПРОЯВЛЕНИЕ КУЛЬТУРЫ ЗАКОНОТВОРЧЕСТВА (ПРОДОЛЖЕНИЕ)
}

\author{
Баранов В.М., Лаврентьев A.P.
}

Аннотация: Культура законотворчества имманентно отражает уровень культуры в соответствующем обществе. Соответственно, культура законотворчества предполагает несколько взаимосвязанных аспектов изучения: определенный результат развития культуры общества на данном этапе; форма человеческой деятельности в области правотворчества; показатель уровня правовой культуры общества. Одним из проявлений культуры законотворчества, на наш взгляд, выступает работа «над ошибками». Как и любой вид человеческой деятельности, законотворчество не свободно от недостатков, некоторые из которых можно отнести к ошибкам - непреднамеренным отклонениям от правильных действий, поступков и мыслей, которые приводят к разнице между ожидаемой или измеренной и реальной величиной. Метод или методология исследования: диалектика, абстрагирование, анализ, синтез, дедукиия, формально-юридическийметод, метод межотраслевых юридических исследований. В последнее время четко наметилось несколько тенденций систематизации в российском законодательстве. При этом общая концепция систематизации не регламентирована и можно рассуждать о формах, видах, содержании и иных ее элементах. Важное значение для выявления и раскрытия рассматриваемых преступлений имеет учет того, что все они сходны $в$ основных принципиальных чертах с точки зрения механизма следообразования, круга и характера носителей и источников криминалистический значимой информации. Это сходство обусловлено в первую очередь закономерной связью преступлений с экономической деятельностью, а также теми закономерностями, которые лежат в основе этой деятельности.

Ключевые слова: Предупреждение, преступность, профилактика, профилактика преступности, статистика преступности, вред, государственное управление, преступление, обращцение, статистические данные. 
Одним из важнейших индикаторов культуры законотворчества и эффективным способом преодоления ошибок в праве выступает общественное обсуждение законопроектов. Полагаем, что общественное обсуждение законопроектов можно рассматривать как форму (способ, прием) экспертизы проекта нормативного правового акта, поэтому оно (обсуждение) может быть предусмотрено при осуществлении других форм прямой демократии, например, в ходе проведения публичных слушаний. Правовое регулирование оснований, порядка и иных процедур публичных слушаний в ст. 28 Федерального закона от 6 октября 2003 г. № 131-Ф3 «Об общих принципах организации местного самоуправления в Российской Федерации» [1], ст. 28 Градостроительного кодекса Российской Федерации [2], законах субъектов Российской Федерации, актах органов исполнительной власти, муниципальных нормативных актах существенно различается. Общественное обсуждение можно реализовать путем направления в органы власти обращений граждан [3] с предложениями по проектам нормативных правовых актов. Общественное обсуждение названо формой осуществления общественного контроля [4].

Заметим также, что общественное обсуждение - не единственная форма экспертизы проектов нормативных правовых актов со стороны институтов гражданского общества. Например, утвержден специальный Состав нормативных правовых актов и иных документов, включая программные, разрабатываемых федеральными органами исполнительной власти, которые не могут быть приняты без предварительного обсу- ждения на заседаниях общественных советов при этих федеральных органах исполнительной власти [5]. Закреплена возможность проведения Общественной палатой Российской Федерации [6] общественной экспертизы проектов нормативных правовых актов. Предусмотрено проведение обязательной [7] независимой антикоррупционной экспертизы [9] проектов нормативных правовых актов [8], но эффективность данного института оказалась низкой: количество независимых экспертов [10] и проведенных ими экспертиз незначительно. При органах законодательной власти создаются консультативно-совещательные органы: например, в Нижегородской области создан научно-консультативный совет при Законодательном Собрании. Сравнительно недавно в рамках создания государственной автоматизированной системы «Законотворчество» разработан Парламентский портал, функционал которого предоставляет также возможность проведения общественного обсуждения законодательных инициатив в социальных сетях. Общественная экспертиза проектов нормативных актов осуществляется «Открытым правительством».

Правовые основы общественного обсуждения проектов нормативных правовых актов активно формируются в последние годы, но утверждать, что система сложилась, на наш взгляд, пока рано. В прилагаемой таблице 5 представлены некоторые результаты сравнения процедур общественного обсуждения проектов нормативных правовых актов, предусмотренных действующими [11] в современной России нормативными правовыми актами. 
Поэтому в ряде субъектов Российской Федерации предложены оригинальные формы систематизации регионального законодательства, которое, как официально констатируется, в основном сформировано. Данный вывод подтверждается результатами подготовленного Советом Федерации Федерального Сoбрания Российской Федерации еще три года назад Доклада о состоянии законодательства в Российской Федерации за 20 лет и аналогичных региональных докладов (например, Доклад Законодательного Собрания Нижегородской области «О состоянии законодательства Нижегородской области и об основных итогах деятельности Законодательного Собрания за 20 лет»).

В настоящее время к элементам законодательства Нижегородской области можно отнести несколько групп нормативных правовых актов:

1. Устав Нижегородской области и законы, которыми в него внесены изменения и дополнения.

2. Базовые (основные) законы Нижегородской области.

3. Иные законы Нижегородской области.

4. Нормативные правовые акты Губернатора Нижегородской области и Правительства Нижегородской области.

5. Нормативные правовые акты министерств и иных органов исполнительной власти Нижегородской области.

6. Нормативные правовые акты иных государственных органов Нижегородской области.

К базовым (основным) законам Нижегородской области, по нашему мнению, можно отнести все законы (на сегодня их из более чем 2000 законов к базовым можно отнести только около 200), за исключением законов о внесении изменений и дополнений в ранее принятые законы и специальных законов:

- о бюджетах;

- о наделении органов местного самоуправления отдельными государственными полномочиями;

- о правоприменении (например, об установлении величины прожиточного минимума пенсионера, о преобразовании муниципальных образований, об утверждении границ и состава территорий муниципальных образований, о перераспределении собственности между публично-правовыми образованиями, об утверждении программ и инвестиционных соглашений, о роспуске представительного органа муниципального образования и т. п.).

Полагаем, что среди базовых законов Нижегородской области, в свою очередь, можно вычленить группу «уставных» законов (по аналогии с федеральными конституционными законами в федеральном законодательстве), наличие которых прямо предусмотрено Уставом Нижегородской области. Таковых не более 25 законов Нижегородской области. Принятие «уставных» законов субъектов Российской Федерации не противоречит Конституции Российской Федерации, в которой применены термины: «конституция и законодательство», «устав и законодательство» (ч. 2 ст. $5)$, «конституций и законов республик, уставов, законов и иных нормативных правовых актов краев, областей, городов федерального значения, автономной области, автономных округов» (п. «а» ч. 1 ст. 72), «законы и иные нормативные 
правовые акты субъекта Российской Федерации» (ч. 2, 3, 5 ст. 76), «нормативные правовые акты субъекта Российской Федерации» (ч. 6 ст. 76).

Следовательно целесообразно предусмотреть введение дополнительного иерархического признака законов субъектов Российской Федерации в Федеральном законе от 6 октября 1999 г. № 184Ф3 «Об общих принципах организации законодательных (представительных) и исполнительных органов государственной власти субъектов Российской Федерации», который не исключает понятие «уставные» законы субъектов Российской Федерации, поскольку в нем по сравнению с Конституцией Российской Федерации намного больше вариантов терминов в отношении законодательства субъектов Российской Федерации, в том числе такие как «конституция (устав) и законы субъекта Российской Федерации», «законодательное регулирование» (п. «б» ч. 1 ст. 5). Вероятно, что в Федеральном законе от 6 октября 1999 г. № 184-Ф3 «Об общих принципах организации законодательных (представительных) и исполнительных органов государственной власти субъектов Российской Федерации» потребуется предусмотреть усложненную процедуру принятия и внесения изменений в уставные законы субъекта Российской Федерации (в том числе ограничение на рассмотрение таких законопроектов в первоочередном порядке, обязательность их вынесения на публичные слушания), по аналогии с процедурой принятия Устава области, а также приоритет «уставных» законов по отношению к иным законам.

Бурное законотворчество выступает неиссякаемым источником для приклад- ных исследований законотворческих ошибок. Например, в современной России развитие местного самоуправления связано с введением в действие Федерального закона от 6 октября 2003 г. № 131-Ф3 «Об общих принципах организации местного самоуправления в Российской Федерации» (далее - Федеральный закон № 131-Ф3), поскольку с момента его принятия и до 1 января 2009 г. был установлен переходный период - по сути, очередной этап реформы местного самоуправления. В то же время в Федеральный закон № 131-Ф3 с момента его принятия внесено более 120 поправок, его текст перестал быть целостным, более трех четвертей содержания отличается от его первоначальной редакции

Наиболее важные изменения, на наш взгляд, были внесены в 2014 г. федеральными законами № 136-Ф3 и № 165-Ф3, которые радикально изменили концепцию законодательного регулирования местного самоуправления в стране, послужили началом нового этапа муниципального строительства по трем направлениям: введены новые виды муниципальных образований - городской округ с внутригородским делением и, соответственно, внутригородской район; разграничены перечни вопросов местного значения городских и сельских поселений, установлен «неснижаемый уровень полномочий» из 13 вопросов; существенно расширены полномочия субъектов Российской Федерации в области организации местного самоуправления. В феврале 2015 г. [12] появилась четвертая новация - введен новый способ избрания главы муниципального образования (представительным органом муниципального образования из числа 
кандидатов, представленных конкурсной комиссией по результатам конкурса) и варианты исполнения им полномочий главы местной администрации.

Таким образом, основой нового этапа муниципального строительства явилось существенное повышение роли субъектов Российской Федерации в организации местного самоуправления на своих территориях, что, как отметил в своем «знаковом» решении [13] Конституционный Суд Российской Федерации, «отвечает природе и правовым основам федеративного государства».

В соответствии с п. «н» ч. 1 ст. 72 Конституции Российской Федерации, Федеральным законом от 6 октября 1999 г. № 184-Ф3 «Об общих принципах организации законодательных (представительных) и исполнительных органов государственной власти субъектов Российской Федерации» и Федеральным законом № 131-Ф3 субъекты Российской Федерации и ранее были наделены значительными полномочиями в области правового регулирования местного самоуправления. В частности, Федеральный закон № 131-Ф3 предусматривал более 70 прямых отсылок к законам субъектов Российской Федерации. Теперь субъекты Российской Федерации наделены дополнительными полномочиями по территориальной организации муниципальной власти, перераспределения полномочий между органами местного самоуправления и органами государственной власти субъекта Российской Федерации, установления системы местного самоуправления (определение порядка формирования, полномочий, сроков полномочий, подотчетности, подконтрольности органов местного самоуправления).
В ходе «муниципальной реформы» субъекты Российской Федерации:

- оставили без внимания возможность образования городских округов с внутригородским делением (эксперимент проводится в Челябинске);

- воспользовались правом перераспределять полномочия;

- изменили способ формирования представительных органов муниципальных районов: только путем делегирования (в 24 субъектах Российской Федерации установлен единственный способ, в 8 - для некоторых муниципальных районов); только на выборах - в 34; оба способа - в 10; и всего в 7 - право предоставлено регулировать уставом муниципального образования;

- по вопросу избрания главы муниципального образования первоначально стали отказываться от прямых выборов в пользу избрания глав из числа депутатов представительных органов, однако в связи с введением в феврале 2015 г. нового способа избрания главы муниципального образования большинство регионов (45) перешли на него.

Но на этом «муниципальная реформа» не завершена - резолютивная часть постановления Конституционного Суда Российской Федерации от 1 декабря 2015 г. № 30-П требует от субъектов Российской Федерации вернуться к законам, принятым ими в сфере организации муниципальной власти, и определить в них критерии, которые будут применяться с целью установления единственно возможного или альтернативного вариантов формирования органов местного самоуправления в муниципальных образованиях. Необходимые изменения должны были быть внесены в течение 
шести месяцев со дня вступления в силу решения суда - до 1 июня 2016 г.

Ряд субъектов Российской Федерации уже внесли изменения в ранее принятые законы субъектов Российской Федерации в целях реализации названного постановления Конституционного Суда Российской Федерации (Волгоградская, Кемеровская области и Хабаровский край), определив такие критерии безальтернативного способа формирования представительного органа и избрания главы муниципального образования, как: «расположение суда и (или) территориальных органов (подразделения) федеральных органов исполнительной власти и являющегося административным центром муниципального района» [14], «отнесение муниципальных образований к следующим видам муниципальных образований: городские округа и муниципальные районы» [15] и «если органы местного самоуправления соответствующего муниципального образования (муниципального района, городского округа) наделены законами отдельными государственными полномочиями; находится постоянное судебное присутствие в составе областного суда, образованное в соответствии с федеральным законом, и (или) численность населения в котором составляет свыше 500 тыс. человек» [16].

В соответствии с п. «н» ч. 1 ст. 72 Конституции Российской Федерации [17], федеральными законами от 6 октября 1999 г. № 184-Ф3 «Об общих принципах организации законодательных (представительных) и исполнительных органов государственной власти субъектов Российской Федерации» [18] и от 6 октября 2003 г. № 131-Ф3 «Об общих принципах организации местного самоуправления в Российской Федерации» [19] субъекты Российской Федерации наделены полномочиями в области правового регулирования местного самоуправления. В частности, Федеральный закон № 131-Ф3 предусматривает более 70 прямых отсылок к законам субъектов Российской Федерации

В настоящее время в Нижегородской области принято и действует около 20 базовых законов Нижегородской области, которые регулируют отдельные вопросы организации местного самоуправления в области. Помимо базовых законов Нижегородской области менее значимые вопросы организации муниципальной власти в области регулируют не менее 40 законов Нижегородской области. Законодательство Нижегородской области о местном самоуправлении представляет собой слабо согласованный массив нормативных правовых актов, что обусловлено множеством объективных и субъективных обстоятельств. Поскольку массив законов области принимался в разное время, в разных обстоятельствах, то это повлекло наличие ошибок, пробелов, коллизий и иных дефектов в законах Нижегородской области о местном самоуправлении.

В субъектах Российской Федерации есть примеры систематизации законодательства о местном самоуправлении. Так, из четырнадцати субъектов Российской Федерации, расположенных на территории Приволжского федерального округа, в восьми субъектах (Кировская область, Оренбургская область, Республика Марий Эл, Чувашская Республика, Республика Татарстан, Удмуртская Республика, Пензенская область, Ре- 
спублика Башкортостан) приняты «единые» законы об организации местного самоуправления. При этом законы пяти из восьми указанных субъектов Российской Федерации имеют относительно сходную структуру.

Отдельного внимания заслуживает вопрос обеспечения доступа к актуальным редакциям текстов законов, принимаемых как Государственной Думой России, так и законодательными (представительными) органами государственной власти субъектов Российской Федерации. Требования Федерального закона от 9 февраля 2008 г. № 8-Ф3 «Об обеспечении доступа к информации органов государственной власти и органов местного самоуправления» не выполняются, поскольку официальные (признаем, в настоящее время более разнообразные) традиционные на бумажных носителях и электронные ресурсы позволяют получить информацию об аутентичных текстах законов. Но эти тексты размещены без возможности ознакомиться с актуальной редакцией текста закона. Актуальные редакции предлагают либо коммерческие справочные правовые системы, либо официальные ресурсы (например, у Минюста России - zakon. scli.ru), которые имеют ограниченные сервисы для использования и порой значительные временные затраты.

Полагаем, необходимо провести работу по систематизации нормативного правового материала, начав с официального издания текстов федеральных законов в актуальной редакции, а в необходимых случаях - проведения инкорпорации по ряду сфер правового регулирования, что позволит сформировать своеобразный эталонный банк федеральных законов, над совершенствованием которого будет продолжена работа в последующем.

Таким образом, в современной Российской Федерации культура законотворчества на федеральном уровне может и должна выступать образцом для регионального законотворчества. На наш взгляд, необходимо минимизировать ошибки путем расширения спектра участников правотворческого процесса и правообразования в целом.

\section{Библиография:}

1. Гольцендорф Ф. Роль общественного мнения в государственной жизни. СПб., 1881; Тард Габриэль. Общественное мнение и толпа. М., 1902; Хвостов В.М. Общественное мнение и политические партии. М., 1906; Чичерин Б.Н. О народном представительстве. СПб., 1866.

2. Горшков М.К. Общественное мнение: история и современность. М.: Политиздат, 1988; Сафаров Р.А. Общественное мнение в советской демократии. М., 1982; Уледов А.К. Общественное мнение советского общества. М., 1963.

3. Карагод Н.В. Преемственность и комплексность правового регулирования общественных отношений, связанных с обсуждением населением проектов правовых актов и вопросов местного значения // Конституционное и муниципальное право. 2010. № 8. С. 65. 
4. Собрание законодательства РФ. 2003. № 40, ст. 3822.

5. Российская газета. 2004. 30 декабря.

6. О порядке рассмотрения обращений граждан Российской Федерации: федеральный закон от 2 мая 2006 г. № 59-Ф3 // Российская газета. 2006. 5 мая.

7. Ст. 24 Федерального закона от 21 июля 2014 г. № 212-Ф3 «Об основах общественного контроля в Российской Федерации» // Российская газета. 2014. 23 июля.

8. Об утверждении состава нормативных правовых актов и иных документов, включая программные, разрабатываемых федеральными органами исполнительной власти, которые не могут быть приняты без предварительного обсуждения на заседаниях общественных советов при этих федеральных органах исполнительной власти: постановление Правительства Российской Федерации от 1 сентября 2012 г. № 877 // Собрании законодательства Российской Федерации. 2012. № 37, ст. 4997.

9. Ст. 18-19 Федерального закона от 4 апреля 2005 г. № 32-Ф3 «Об Общественной палате Российской Федерации» // Собрание законодательства РФ. 2005. № 15, ст. 1277.

10. П. 4.1 Правил подготовки нормативных правовых актов федеральных органов исполни-тельной власти и их государственной регистрации: утв. постановлением Правительства Российской Федерации от 13 августа 1997 г. № 1009 // Российская газета. 1997. 21 августа.

11. Ст. 5 Федерального закона от 17 июля 2009 г. № 172-ФЗ «Об антикоррупционной экспертизе нормативных правовых актов и проектов нормативных правовых актов» // Собрание законодательства Российской Федерации. 2009. № 29, ст. 3609.

12. Правила проведения антикоррупционной экспертизы нормативных правовых актов и проектов нормативных правовых актов: утв. постановлением Правительства Российской Федерации от 26 февраля 2010 г. № 96 // Российская газета. 2010. 5 марта.

13. По данным Министерства юстиции РФ на 2 апреля 2015 года аккредитовано 2047 независимых экспертов: 1731 физическое лицо и 316 юридических лиц. URL: http://minjust.ru/activity/legislative/anticorrekspert (дата обращения: 30.05.2015).

14. Так, постановлением Правительства Российской Федерации от 29 марта 2014 г. № 246 признано утратившим силу постановление Правительства Российской Федерации от 22 февраля 2012 г. № 159, которым были утверждены Правила проведения общественного обсуждения проектов федеральных конституционных законов и федеральных законов, более двух лет применявшееся параллельно с актом большей юридической силы - Указом Президента РФ от 9 февраля 2011 г. № 167 - и, как ни странно, во многом расходившееся с названным указом по процедурам общественного обсуждения аналогичных документов.

15. Об общественном обсуждении проектов федеральных конституционных законов и федеральных законов: указ Президента Российской Федерации от 9 февраля 2011 г. № 167 // Российская газета. 2011. 11 февраля. 
16. О порядке раскрытия федеральными органами исполнительной власти информации о под-готовке проектов нормативных правовых актов и результатах их общественного обсуждения: постановление Правительства Российской Федерации от 25 августа 2012 г. № 851 // Российская газета. 2012. 31 августа.

17. Отчет «Российское законодательство: 20 лет развития в русле новой Конституции Российской Федерации» / отв. ред. А.А. Клишас, В.Н. Плигин. М.: Совет Федерации, 2013. Т. 1 (приложение 1 к разделу 3).

18. О внесении изменений в статьи 32 и 33 Федерального закона «Об основных гарантиях избирательных прав и права на участие в референдуме граждан Российской Федерации» и Федеральный закон «Об общих принципах организации местного самоуправления в Российской Федерации»: федеральный закон от 3 февраля 2015 г. № 8-Ф3 // Собрание законодательства РФ. 2015. № 6, ст. 886.

19. По делу о проверке конституционности частей 4, 5 и 5.1 статьи 35 , частей 2 и 3.1 статьи 36 Федерального закона «Об общих принципах организации местного самоуправления в Российской Федерации» и части 1.1 статьи 3 Закона Иркутской области «Об отдельных вопросах формирования органов местного самоуправления муниципальных образований Иркутской области» в связи с запросом группы депутатов Государственной Думы: постановление Конституционного Суда Российской Федерации от 1 декабря 2015 г. № 30-П // Собрание законодательства РФ. 2015. № 50, ст. 7226.

20. О внесении изменений в Закон Волгоградской области от 29 мая 2014 г. N 70 ОД «О некоторых вопросах формирования органов местного самоуправления в Волгоградской области»: закон Волгоградской области от 30 декабря 2015 г. № 243-ОД. URL: http://www.pravo.gov.ru (дата обращения: 04.01.2016).

21. О внесении изменений в Закон Хабаровского края «Об отдельных вопросах организации местного самоуправления в Хабаровском крае»: закон Хабаровского края от 10 марта 2016 г. № 170. URL: http://www.pravo.gov.ru (дата обращения: 15.03.2016).

22. О внесении изменения в статью 2 Закона Кемеровской области «Об отдельных вопросах организации и деятельности органов местного самоуправления муниципальных образований»: закон Кемеровской области от 25 декабря 2015 г. № 127-O3. URL: http://www.pravo.gov.ru (дата обращения: 30.12.2015).

23. www.pravo.gov.ru, 2014, 1 августа / 0001201408010002.

24. Собрание законодательства РФ. 1999. № 42, ст. 5005.

25. Собрание законодательства РФ. 2003. № 40, ст. 3822.

\section{References (transliterated):}

1. Gol'tsendorf F. Rol' obshchestvennogo mneniya v gosudarstvennoi zhizni. SPb., 1881; Tard Gabriel'. Obshchestvennoe mnenie i tolpa. M., 1902; Khvostov V.M. Ob- 
shchestvennoe mnenie i politicheskie partii. M., 1906; Chicherin B.N. O narodnom predstavitel'stve. SPb., 1866.

2. Gorshkov M.K. Obshchestvennoe mnenie: istoriya i sovremennost'. M.: Politizdat, 1988; Safarov R.A. Obshchestvennoe mnenie v sovetskoi demokratii. M., 1982; Uledov A.K. Obshchestvennoe mnenie sovetskogo obshchestva. M., 1963.

3. Karagod N.V. Preemstvennost' i kompleksnost' pravovogo regulirovaniya obshchestvennykh otnoshenii, svyazannykh s obsuzhdeniem naseleniem proektov pravovykh aktov i voprosov mestnogo znacheniya // Konstitutsionnoe i munitsipal'noe pravo. 2010. № 8. S. 65.

4. Sobranie zakonodatel’stva RF. 2003. № 40, st. 3822.

5. Rossiiskaya gazeta. 2004. 30 dekabrya.

6. O poryadke rassmotreniya obrashchenii grazhdan Rossiiskoi Federatsii: federal'nyi zakon ot 2 maya 2006 g. № 59-FZ // Rossiiskaya gazeta. 2006. 5 maya.

7. St. 24 Federal'nogo zakona ot 21 iyulya 2014 g. № 212-FZ «Ob osnovakh obshchestvennogo kontrolya v Rossiiskoi Federatsii»// Rossiiskaya gazeta. 2014. 23 iyulya.

8. Ob utverzhdenii sostava normativnykh pravovykh aktov i inykh dokumentov, vklyuchaya programmnye, razrabatyvaemykh federal'nymi organami ispolnitel'noi vlasti, kotorye ne mogut byt' prinyaty bez predvaritel'nogo obsuzhdeniya na zasedaniyakh obshchestvennykh sovetov pri etikh federal'nykh organakh ispolnitel'noi vlasti: postanovlenie Pravitel'stva Rossiiskoi Federatsii ot 1 sentyabrya 2012 g. № 877 // Sobranii zakonodatel'stva Rossiiskoi Federatsii. 2012. № 37, st. 4997.

9. St. 18-19 Federal'nogo zakona ot 4 aprelya 2005 g. № 32-FZ «Ob Obshchestvennoi palate Rossiiskoi Federatsii» // Sobranie zakonodatel’stva RF. 2005. № 15, st. 1277.

10. P. 4.1 Pravil podgotovki normativnykh pravovykh aktov federal'nykh organov ispolnitel'noi vlasti i ikh gosudarstvennoi registratsii: utv. postanovleniem Pravitel'stva Rossiiskoi Federatsii ot 13 avgusta 1997 g. № 1009 // Rossiiskaya gazeta. 1997. 21 avgusta.

11. St. 5 Federal'nogo zakona ot 17 iyulya 2009 g. № $172-\mathrm{FZ}$ «Ob antikorruptsionnoi ekspertize normativnykh pravovykh aktov i proektov normativnykh pravovykh aktov» // Sobranie zakonodatel'stva Rossiiskoi Federatsii. 2009. № 29, st. 3609.

12. Pravila provedeniya antikorruptsionnoi ekspertizy normativnykh pravovykh aktov i proektov normativnykh pravovykh aktov: utv. postanovleniem Pravitel'stva Rossiiskoi Federatsii ot 26 fevralya 2010 g. № 96 // Rossiiskaya gazeta. 2010. 5 marta.

13. Po dannym Ministerstva yustitsii RF na 2 aprelya 2015 goda akkreditovano 2047 nezavisimykh ekspertov: 1731 fizicheskoe litso i 316 yuridicheskikh lits. URL: http:// minjust.ru/activity/legislative/anticorrekspert (data obrashcheniya: 30.05.2015).

14. Tak, postanovleniem Pravitel’stva Rossiiskoi Federatsii ot 29 marta 2014 g. № 246 priznano utrativshim silu postanovlenie Pravitel'stva Rossiiskoi Federatsii ot 22 fevralya 2012 g. № 159, kotorym byli utverzhdeny Pravila provedeniya obshchestvennogo obsuzhdeniya proektov federal'nykh konstitutsionnykh zakonov i federal'nykh zakonov, bolee dvukh let primenyavsheesya parallel'no s aktom bol'shei yuridicheskoi sily - Ukazom Prezidenta RF ot 9 fevralya 2011 g. № 167 - i, kak ni stranno, vo 
mnogom raskhodivsheesya s nazvannym ukazom po protseduram obshchestvennogo obsuzhdeniya analogichnykh dokumentov.

15. Ob obshchestvennom obsuzhdenii proektov federal'nykh konstitutsionnykh zakonov i federal'nykh zakonov: ukaz Prezidenta Rossiiskoi Federatsii ot 9 fevralya $2011 \mathrm{~g}$. № 167 // Rossiiskaya gazeta. 2011. 11 fevralya.

16. O poryadke raskrytiya federal'nymi organami ispolnitel'noi vlasti informatsii o podgotovke proektov normativnykh pravovykh aktov i rezul'tatakh ikh obshchestvennogo obsuzhdeniya: postanovlenie Pravitel'stva Rossiiskoi Federatsii ot 25 avgusta 2012 g. № 851 // Rossiiskaya gazeta. 2012. 31 avgusta.

17. Otchet «Rossiiskoe zakonodatel'stvo: 20 let razvitiya v rusle novoi Konstitutsii Rossiiskoi Federatsii»/ otv. red. A.A. Klishas, V.N. Pligin. M.: Sovet Federatsii, 2013. T. 1 (prilozhenie $1 \mathrm{k}$ razdelu 3 ).

18. O vnesenii izmenenii v stat'i 32 i 33 Federal'nogo zakona «Ob osnovnykh garantiyakh izbiratel'nykh prav i prava na uchastie $\mathrm{v}$ referendume grazhdan Rossiiskoi Federatsii» i Federal'nyi zakon «Ob obshchikh printsipakh organizatsii mestnogo samoupravleniya v Rossiiskoi Federatsii»: federal'nyi zakon ot 3 fevralya 2015 g. № 8-FZ // Sobranie zakonodatel’stva RF. 2015. № 6, st. 886.

19. Po delu o proverke konstitutsionnosti chastei 4, 5 i 5.1 stat'i 35, chastei 2 i 3.1 stat'i 36 Federal'nogo zakona «Ob obshchikh printsipakh organizatsii mestnogo samoupravleniya v Rossiiskoi Federatsii» i chasti 1.1 stat'i 3 Zakona Irkutskoi oblasti «Ob otdel'nykh voprosakh formirovaniya organov mestnogo samoupravleniya munitsipal'nykh obrazovanii Irkutskoi oblasti» v svyazi s zaprosom gruppy deputatov Gosudarstvennoi Dumy: postanovlenie Konstitutsionnogo Suda Rossiiskoi Federatsii ot 1 dekabrya 2015 g. № 30-P // Sobranie zakonodatel'stva RF. 2015. № 50, st. 7226.

20. O vnesenii izmenenii v Zakon Volgogradskoi oblasti ot 29 maya 2014 g. N 70-OD «O nekotorykh voprosakh formirovaniya organov mestnogo samoupravleniya v Volgogradskoi oblasti»: zakon Volgogradskoi oblasti ot 30 dekabrya 2015 g. № 243-OD. URL: http://www.pravo.gov.ru (data obrashcheniya: 04.01.2016).

21. O vnesenii izmenenii v Zakon Khabarovskogo kraya «Ob otdel'nykh voprosakh organizatsii mestnogo samoupravleniya v Khabarovskom krae»: zakon Khabarovskogo kraya ot 10 marta 2016 g. № 170. URL: http://www.pravo.gov.ru (data obrashcheniya: 15.03.2016).

22. O vnesenii izmeneniya v stat'yu 2 Zakona Kemerovskoi oblasti «Ob otdel'nykh voprosakh organizatsii i deyatel'nosti organov mestnogo samoupravleniya munitsipal'nykh obrazovanii»: zakon Kemerovskoi oblasti ot 25 dekabrya 2015 g. № 127-OZ. URL: http://www.pravo.gov.ru (data obrashcheniya: 30.12.2015).

23. www.pravo.gov.ru, 2014, 1 avgusta / 0001201408010002.

24. Sobranie zakonodatel'stva RF. 1999. № 42, st. 5005.

25. Sobranie zakonodatel’stva RF. 2003. № 40, st. 3822. 